\title{
Real-Time Determination of Overall Heat Transfer Coefficient from the Seebeck Effect by Using Adaptive Learning-Rate Optimization
}

\author{
Nataporn Korprasertsak ${ }^{1}$ and Thananchai Leephakpreeda ${ }^{1, *}$ \\ ${ }^{1}$ School of Manufacturing Systems and Mechanical Engineering, Sirindhorn International Institute of Technology, Thammasat University \\ P.O. Box 22, Thammasat-Rangsit Post Office, Pathum Thani, 12121, Thailand
}

\begin{abstract}
It is challenging to determine the actual overall heat transfer coefficient under thermal conditions during processes. In a conventional approach, they are obtained as a constant with the empirical formula for the given conditions. In this study, the Adaptive moment estimation (Adam) technique is investigated for adaptive learning-rate optimization in the real-time determination of the overall heat transfer coefficient via the Seebeck effect in the thermoelectric modules. Two thermoelectric modules detect heat transfer as solid surfaces exposed to the outdoor air. The principle of energy balance and the Seebeck effect determine the overall h eat transfer co efficients o ver time. The heating/cooling p rocess of a co pper $p$ late is considered with exposure to the outdoor a ir. $T$ he overall he at transfer coefficient is de termined $w$ ith the proposed methodology over time. The temperature of the copper plate is numerically determined by the mathematical models with the obtained values of the overall heat transfer coefficient. It is confirmed that the calculated values of temperature are close to the measured values, with $\mathrm{RMSE}=0.07{ }^{\circ} \mathrm{C}$.
\end{abstract}

\section{Introduction}

In thermal analysis, the overall heat transfer coefficient is an $i$ mportant $p$ arameter o $\mathrm{f} h$ eat $t$ ransfer i $\mathrm{n}$ arious engineering ap plications. S everal r esearch works have experimentally i nvestigated $t$ he $o$ verall $h$ eat $t$ ransfer coefficient, to improve the performance and efficiency of certain $p$ rocesses. $F$ or ex ample, an em pirical formula was u sed to increase the thermal ef ficiency and reduce energy co nsumption in thermal $p$ rocesses $s$ uch as fintype $h$ eat ex changes in el ectronic $d$ evices [ 1] an $\mathrm{d} t$ he heat loss of building facades [2], respectively. Recently, the $\mathrm{d}$ etermination o $\mathrm{ft}$ he convective $\mathrm{h}$ eat $\mathrm{t}$ ransfer coefficient under actual convection processes over time has been proposed, using thermoelectric modules based on $\mathrm{t}$ he Seebeck e ffect [3]. I $\mathrm{t}$ was found th at the convective heat $t$ ransfer co efficient was $d$ ependent o $n$ time-variant properties of air and thermal surfaces. To determine $t$ he co nvective $h$ eat $t$ ransfer co efficient, $t$ he recursive o ptimization with $\mathrm{t}$ he gradient $\mathrm{d}$ escent technique is used to search for the ac tual $v$ alues o ver time [ 4]. $\mathrm{H}$ owever, $\mathrm{t}$ he $\mathrm{d}$ ifficulty in e mploying $\mathrm{t}$ he gradient descent approach is that a reasonable step size is required to be adjusted in real time. To o vercome this problem, th e A daptive moment e stimation (Adam) i s proposed $\mathrm{t}$ od etermine $\mathrm{t}$ he $\mathrm{o}$ verall $\mathrm{h}$ eat $\mathrm{t}$ ransfer coefficient i $\mathrm{n} t$ he o ptimization. $\mathrm{P}$ resently, the $\mathrm{A}$ dam technique is one of the most effective adaptive learningrate o ptimization in d eep le arning models. $\mathrm{T}$ he A dam technique $p$ rovided a $f$ ast co nverge $r$ ate with accu rate results [5]. A lso, a majority o f well-known de ep learning libraries supported the Adam technique, such as
Tensorflow, Keras, Caffe, Torch, etc. [6]. Therefore, the Adam te chnique i s a dapted $w$ ith o ptimization for the real-time $\mathrm{d}$ etermination of the o verall heat $\mathrm{t}$ ransfer coefficient via the $\mathrm{S}$ eebeck effect in $\mathrm{t}$ his work. $\mathrm{T}$ his study $i \mathrm{sa} n \mathrm{e}$ xperimental $\mathrm{i}$ nvestigation o $\mathrm{fa}$ heating/cooling $\mathrm{p}$ rocess with $\mathrm{d}$ ynamic e xposure t o the outdoor air.

This paper is organized as follows. In Section 2, the Adam technique is $p$ resented for ad aptive l earning-rate optimization in the real-time determination of the overall heat transfer coefficients. In Section 3, the values of the overall $\mathrm{h}$ eat $\mathrm{t}$ ransfer co efficient in $\mathrm{t}$ he heating/cooling process of a c opper plate in th e o utdoor a ir a re determined o ver $t$ ime $b y t$ he $p$ roposed $t$ echnique, as a case s tudy. $\mathrm{T}$ o v alidate the ef fectiveness, the Adam technique is ap plied to $p$ redict the $t$ emperatures of $t$ he copper plate du ring t he heating/cooling pr ocess i $n$ outdoor a ir with mathematical models. A c omparison between $\mathrm{t}$ he measured $\mathrm{t}$ emperature an $\mathrm{d} t$ he cal culated temperature, which ar e o btained with $\mathrm{t}$ he $\mathrm{o}$ verall $\mathrm{h}$ eat transfer coefficient, is shown. The conclusion about the viability of th $\mathrm{e}$ proposed te chnique in the $\mathrm{r}$ eal-time determination of the overall heat transfer coefficient via the Seebeck effect is stated in Section 4

\section{Real-time determination of overall heat transfer coefficients by using adaptive learning-rate optimization}

In thermal analysis, the overall heat transfer coefficient of a solid surface exposed to the outdoor air is comprised 
of a co nvective $h$ eat $t$ ransfer co efficient an $\mathrm{d}$ a $\mathrm{r}$ adiant heat transfer coefficient [7], as expressed by:

$$
h_{T}=h_{c}+h_{r}
$$

where $h_{T}$ is the overall heat transfer coefficient, $h_{c}$ is the convective heat transfer coefficient, and $h_{r}$ is the radiant heat transfer coefficient.

To d etermine the o verall heat $t$ ransfer co efficients over time, the Seebeck effect of a thermoelectric module is applied when the heat transfer takes place, as shown in Figure 1. O ne s urface of the thermoelectric module is faced $\mathrm{t} o \mathrm{a} \mathrm{n}$ a ir a nd s unlight while a nother surface i s attached with a $h$ eat $\mathrm{s}$ ink. $\mathrm{T}$ he $\mathrm{p}$ rinciple o f en ergy balance i s u sed $t$ o d etermine $t$ he $t$ emperature o $f t$ he ceramic substrate at the hot side:

$$
m_{c s} c_{c s} \frac{d T_{p h, s}}{d t}=I-h_{T} A_{T}\left(T_{p h, s}-T_{a}\right)-Q_{T, s}
$$

where $m_{c s}$ is the mass of ceramic substrate, $C_{c s}$ is the s pecific h eat o f cer amic s ubstrate, $T_{p h, s}$ is the temperature of cer amic substrate at the hot side, $I$ is the $\mathrm{i}$ ncident ir radiance of sunlight, $A_{T}$ is t he s urface area of $\mathrm{t}$ he $\mathrm{t}$ hermoelectric module, $Q_{T, s}$ is $\mathrm{t}$ he he at transfer through $\mathrm{t}$ he $\mathrm{t}$ hermoelectric m odule $\mathrm{w}$ hen the cold side is induced by a heat sink, and $t$ is the time.

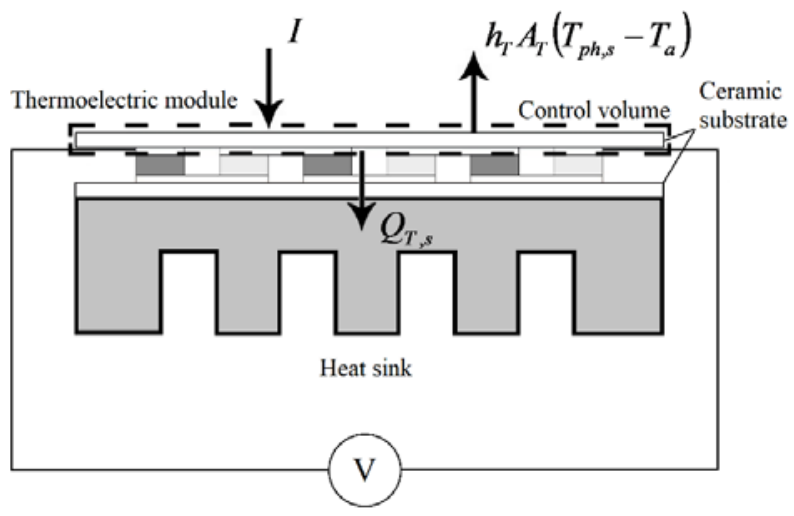

Fig. 1. Real-time determination of the overall heat transfer coefficients via Seebeck effect.

According to the S eebeck ef fect [3], t he S eebeck voltage of the thermoelectric module can be generated when there are temperature differences between the two ceramic s ubstrates of the th ermoelectric module. $T$ he amount o f he at $t$ ransfer $t$ hrough $t$ he $t$ hermoelectric module is determined by:

$$
Q_{T, s}=\frac{k_{T}}{\beta} V
$$

where $V$ is $\mathrm{t}$ he $\mathrm{S}$ eebeck voltage acr oss $\mathrm{t}$ he thermoelectric m odule, $k_{T}$ is the th ermal c onductivity coefficient of a t hermoelectric module, an $\mathrm{d} \beta$ is the Seebeck effect coefficient.

The rate of heat flowing through the thermoelectric module can be determined by the Seebeck voltage across the $t$ hermoelectric module. $\mathrm{T}$ he $\mathrm{d}$ irection of $\mathrm{t}$ he $\mathrm{h}$ eat flow through the thermoelectric module is indicated by the $\mathrm{p}$ olarity o $\mathrm{ft}$ he Seebeck voltage acr oss $\mathrm{t}$ he thermoelectric module.

According to equation (2), the values of the incident irradiance o f $\mathrm{s}$ unlight an $\mathrm{d} t$ he $o$ verall $\mathrm{h}$ eat $\mathrm{t}$ ransfer coefficient are unknown while the temperatures and the Seebeck voltage are measured. To determine the overall heat transfer coefficient, a nother thermoelectric module is at tached in parallel, as shown in Figure 2. However, the heat sink i s c hanged to a $\mathrm{n}$ i nsulated wall. $\mathrm{T}$ his modification $r$ esults $\mathrm{i} \mathrm{nt}$ he temperature $\mathrm{d}$ ifference between the two thermoelectric modules. With the same consideration, the temperature of the cer amic s ubstrate of the thermoelectric module coupled with an insulator at the hot side can be described as:

$$
m_{c s} c_{c s} \frac{d T_{p h, i}}{d t}=I-h_{T} A_{T}\left(T_{p h, i}-T_{a}\right)-Q_{T, i}
$$

where $T_{p h, i}$ is $\mathrm{t}$ he $\mathrm{t}$ emperature o $\mathrm{ft}$ he cer amic substrate at the hot side when an insulator is installed at the cold side, and $Q_{T, i}$ is the heat transfer through the thermoelectric module when the cold side is attached by an insulator.

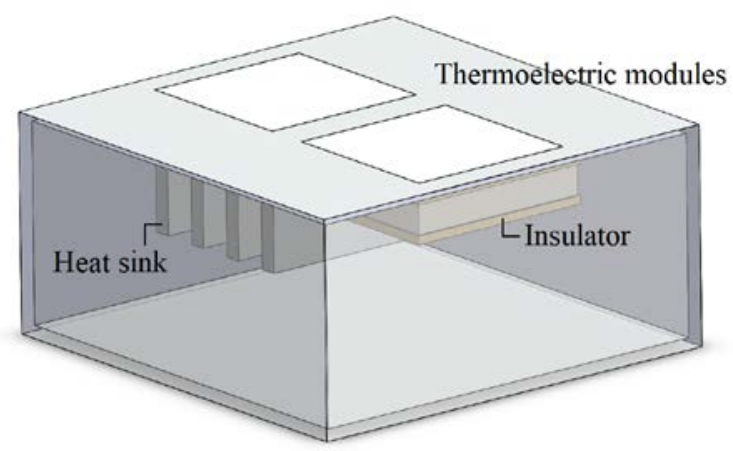

Fig. 2. Two thermoelectric modules coupled with heat sink and insulator.

Equation (2) i s s ubtracted by e quation (4). The incident ir radiance o f $\mathrm{s}$ unlight is e liminated. The temperatures of the ceramic substrates at the hot side are written as:

$m_{c s} c_{c s} \frac{d\left(T_{p h, s}-T_{p h, i}\right)}{d t}=-h_{T} A_{T}\left(T_{p h, s}-T_{p h, i}\right)-\left(Q_{T, s}-Q_{T, i}\right)$

The temperature $d$ ifference $b$ etween $t$ he two thermoelectric modules at $\mathrm{t}$ he $\mathrm{h}$ ot $\mathrm{s}$ ides i s d efined as $Y(t):=T_{p h, s}(t)-T_{p h, i}(t)$ with: 


$$
m_{c s} c_{c s} \frac{d Y}{d t}=-h_{T} A_{T} Y-\left(Q_{T, s}-Q_{T, i}\right)
$$

The $o$ verall $h$ eat $t$ ransfer co efficient can $b$ e determined when the temperature difference between the two thermoelectric modules at the hot side in equation (6) is eq ual $t$ o the $t$ emperature difference that i s o btained from the measurement. The error function is defined as:

$$
E=\frac{1}{2}\left(Y(t)-Y_{m}(t)\right)^{2}
$$

where $Y_{m}$ is the measured value of the temperature difference between the two thermoelectric modules. The backward finite di fference a pproximation is a pplied to equation (6).

$$
\frac{Y(t)-Y(t-\Delta t)}{\Delta t}=-\frac{h_{T}(t) A_{T}}{m_{c s} c_{c s}} Y(t)-\frac{1}{m_{c s} c_{c s}}\left(Q_{T, s}(t)-Q_{T, i}(t)\right)
$$

where $\Delta t$ is the time step.

According to eq uation (9), t he cu rrent t emperature difference can be determined when the previous temperature difference is known.

$$
Y(t)=\frac{Y(t-\Delta t)-\frac{\Delta t}{m_{c s} c_{c s}}\left(Q_{T, S}(t)-Q_{T, i}(t)\right)}{1+\frac{h_{T}(t) A_{T} \Delta t}{m_{c s} c_{c s}}}
$$

By $t$ aking $t$ he $d$ erivative of e quation ( 8), $t$ he derivative of the temperature difference with respect to the overall heat transfer coefficient can be obtained as:

$$
\frac{\partial Y(t)}{\partial h_{T}}=\frac{\frac{\partial Y(t-\Delta t)}{\partial h_{T}}-\frac{A_{T} \Delta t}{m_{c s} c_{c s}} Y(t)}{1+\frac{h_{T}(t) A_{T} \Delta t}{m_{c s} c_{c s}}}
$$

The d erivative of the er ror function with respect to the overall heat transfer coefficient can be determined by:

$$
\frac{\partial E}{\partial h_{T}}=\frac{\partial E}{\partial Y} \frac{\partial Y}{\partial h_{T}}=\left(Y(t)-Y_{m}(t)\right)\left(\frac{\frac{\partial Y(t-\Delta t)}{\partial h_{T}}-\frac{A_{T} \Delta t}{m_{c s} c_{c s}} Y(t)}{1+\frac{h_{T}(t) A_{T} \Delta t}{m_{c s} c_{c s}}}\right)
$$

In this work, the adaptive moment estimation (Adam) algorithm is a pplied, to minimize the e rror function in equation (7):

$$
h_{T}(t+\Delta t)=h_{T}(t)-\eta \frac{\hat{m}(t+\Delta t)}{\sqrt{\hat{v}(t+\Delta t)}+\varepsilon}
$$

With the $\mathrm{b}$ ias $\mathrm{c}$ orrected e stimators for the first and second moments,

$$
\hat{m}(t+\Delta t)=\frac{m(t+\Delta t)}{1-\beta_{1}}
$$

$$
\hat{v}(t+\Delta t)=\frac{v(t+\Delta t)}{1-\beta_{2}}
$$

The $\mathrm{m}$ oving a verages o $\mathrm{f}$ gr adient a nd $\mathrm{t}$ he moving averages of squared gradient are defined as:

$$
m(t+\Delta t)=\beta_{1} m(t)+\left(1-\beta_{1}\right) \frac{\partial E}{\partial h_{T}}
$$

and

$$
v(t+\Delta t)=\beta_{2} v(t)+\left(1-\beta_{2}\right) \frac{\partial E}{\partial h_{T}}
$$

where $\quad h_{T}(t+\Delta t)$ is th e u pdated $\mathrm{v}$ alue o $\mathrm{f}$ th $\mathrm{e}$ overall heat transfer coefficient at the next time, $h_{T}(t)$ is the value of the overall heat transfer coefficient at the current time, $\eta$ is the learning rate or step size, and $\varepsilon$ is the empirical constant used to prevent division by zero in th e i mplementation. $\beta_{1}$ and $\beta_{2}$ are the h yper parameters of the al gorithm, which are the ex ponential decay $r$ ate for $t$ he first momente stimates a nd $t$ he exponential decay rate for the second-moment estimates, respectively.

The initial numerical values of the parameters are in Table 1 . T he derivative o $\mathrm{f}$ th $\mathrm{e} e$ rror $\mathrm{f}$ unction with respect $t$ ot he overall $h$ eat $t$ ransfer co efficient $i n$ equations (15) and (16) is determined by equation (11).

Table 1. Numerical values of parameters.

\begin{tabular}{|c|c|}
\hline Parameters & Numerical values \\
\hline Learning rate or step size, $\eta$ & 0.09 \\
\hline Empirical constants, $\varepsilon$ & $10^{-8}$ \\
\hline $\begin{array}{c}\text { Running average of } \\
\text { the gradient, } \beta_{1}\end{array}$ & 0.9 \\
\hline $\begin{array}{c}\text { Running average of } \\
\text { the squared gradient, } \beta_{2}\end{array}$ & 0.999 \\
\hline $\begin{array}{c}\text { Initial value of overall heat } \\
\text { transfer coefficient, } h_{T}\end{array}$ & 20 \\
\hline $\begin{array}{c}\text { Initial value of moving } \\
\text { average of gradient, } m\end{array}$ & 0 \\
\hline $\begin{array}{c}\text { Initial value of moving } \\
\text { averages of squared gradient, } v\end{array}$ & 0 \\
\hline
\end{tabular}

\section{Results and Discussion}

To a pply $t$ he pr oposed $m$ ethodology i $n \mathrm{r}$ eal $\mathrm{t}$ ime, a $\mathrm{n}$ experiment for temperature prediction of a co pper p late is set up, as shown in Figure 3.

and 


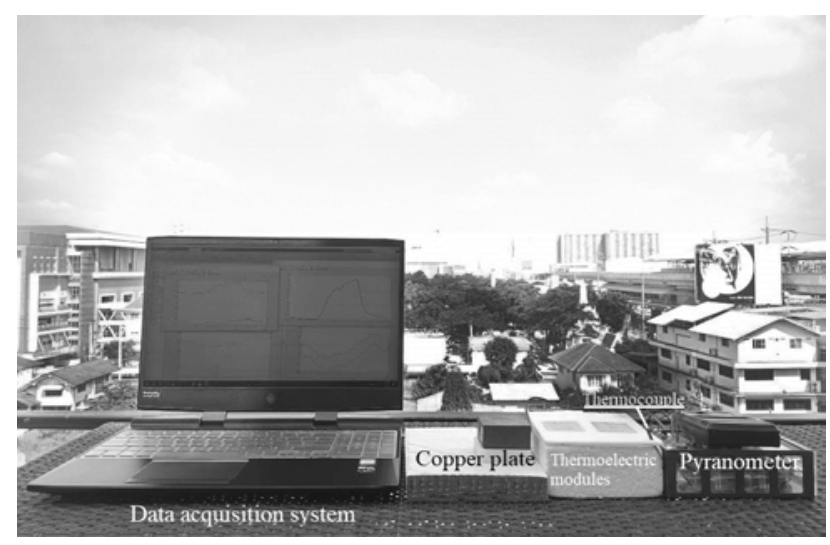

Fig. 3. Experiment of copper plate in outdoor air.

The copper plate is placed in an insulated box where a s ingle s urface i s e xposed to a tmosphere $d$ uring $t$ he daytime. $\mathrm{T}$ he $\mathrm{t}$ emperature o $\mathrm{ft}$ he co pper $\mathrm{p}$ late $\mathrm{i} \mathrm{s}$ governed by the energy balance equation, equation (17).

$$
m_{c} c_{c} \frac{d T}{d t}=I-h_{T} A_{c}\left(T-T_{a}\right)
$$

where $T$ is the temperature of copper plate, $m_{c}$ is the mass of copper plate, $C_{C}$ is the specific heat of the copper plate, and $A_{c}$ is the transferred area of the copper plate.

The $\mathrm{p}$ hysical $\mathrm{p}$ roperties o $\mathrm{ft}$ he $\mathrm{t}$ hermoelectric modules and the copper plate are listed in Table 2. To solve equation (17), the overall heat transfer coefficient, incident irradiance, and air temperature must be known over $t$ ime. $\mathrm{T}$ he $\mathrm{p}$ roposed $\mathrm{t}$ hermoelectric modules ar $\mathrm{e}$ located $n$ ear $t$ he co pper $p$ late $f$ or $d$ etermining $t$ he unknown overall heat transfer of the copper plate to air. A p yranometer ( SolData98HP) with a $n$ acc uracy o $f$ $\pm 3 \% \mathrm{FS}$, a nd a $\mathrm{K}$-type $\mathrm{t}$ hermocouple ar e $\mathrm{u}$ sed $\mathrm{f}$ or measuring solar i rradiance o $\mathrm{n}$ a co pper $\mathrm{p}$ late an $\mathrm{d}$ ai $\mathrm{r}$ temperature, respectively

Table 2. Physical properties and parameters.

\begin{tabular}{|c|c|}
\hline Parameters & Numerical values \\
\hline $\begin{array}{c}\text { Mass of ceramic } \\
\text { substrate, } m_{c s}(\mathrm{~g})\end{array}$ & 4.0456 \\
\hline $\begin{array}{c}\text { Specific heat of ceramic } \\
\text { substrate, } C_{c s}\left(\mathrm{~J} / \mathrm{g}^{\circ} \mathrm{C}\right)\end{array}$ & 0.88 \\
\hline $\begin{array}{c}\text { Seebeck effect } \\
\text { coefficient, } \beta\left(\mathrm{V} /{ }^{\circ} \mathrm{C}\right)\end{array}$ & 0.0424 \\
\hline $\begin{array}{c}\text { Thermal conductivity } \\
\text { coefficient, } k_{T}\left(\mathrm{~W} /{ }^{\circ} \mathrm{C}\right)\end{array}$ & 0.1639 \\
\hline $\begin{array}{c}\text { Mass of copper plate, } m_{c}(\mathrm{~g}) \\
\text { Specific heat of } \\
\text { copper plate, } C_{c}\left(\mathrm{~J} / \mathrm{g}^{\circ} \mathrm{C}\right)\end{array}$ & 28.672 \\
\hline \begin{tabular}{c} 
Area of copper plate, $A_{c}\left(\mathrm{~m}^{2}\right)$ \\
\hline
\end{tabular} & 0.385 \\
\hline
\end{tabular}

The solar radiation flux density and air temperature are observed as illustrated in Figure 4(a). The proposed methodology $\mathrm{i} n \mathrm{~S}$ ection $2 \mathrm{i}$ si mplemented for determining $t$ he va lues o $f$ the $o$ verall heat $t$ ransfer coefficient o ver time. The values of the er ror function for computation performance are plotted against time in Figure 4 (b), as they ar e accep tably s mall. T his r esult indicates that the calculated temperature differences are in good a greement with the measurements. As reported in $\mathrm{F}$ igure 4 (c), $\mathrm{t}$ he va lues o $\mathrm{ft}$ he o verall $\mathrm{h}$ eat $\mathrm{tr}$ ansfer coefficient ar e o btained o ver $t$ ime. Together with $t$ he incident $\mathrm{i}$ rradiance an $\mathrm{d}$ ai $\mathrm{r} t$ emperature, the cal culated values of the overall heat transfer coefficient are inputted into th $\mathrm{e}$ mathematical model o $\mathrm{f}$ th e $\mathrm{c}$ opper $\mathrm{p}$ late in equation (17). F igure 4 (d) s hows a comparison of the simulated $r$ esults o f co pper $p$ late $t$ emperature with measured $\mathrm{v}$ alues. I $\mathrm{t}$ i s o bserved $\mathrm{t}$ hat $\mathrm{t}$ he $\mathrm{s}$ imulated results o f co pper $\mathrm{p}$ late $\mathrm{t}$ emperature $\mathrm{cl}$ osely $\mathrm{t}$ rack $\mathrm{t}$ he measured $v$ alues with RMSE $=0.07{ }^{\circ} \mathrm{C}$. $\mathrm{F}$ urthermore, the simulated results with an estimated overall heat transfer co efficient of $20 \mathrm{~W} / \mathrm{m}^{2} \mathrm{~K}$ ar e comparatively presented with higher d eviations a $\mathrm{s}$ a $\mathrm{c}$ onventional approach.
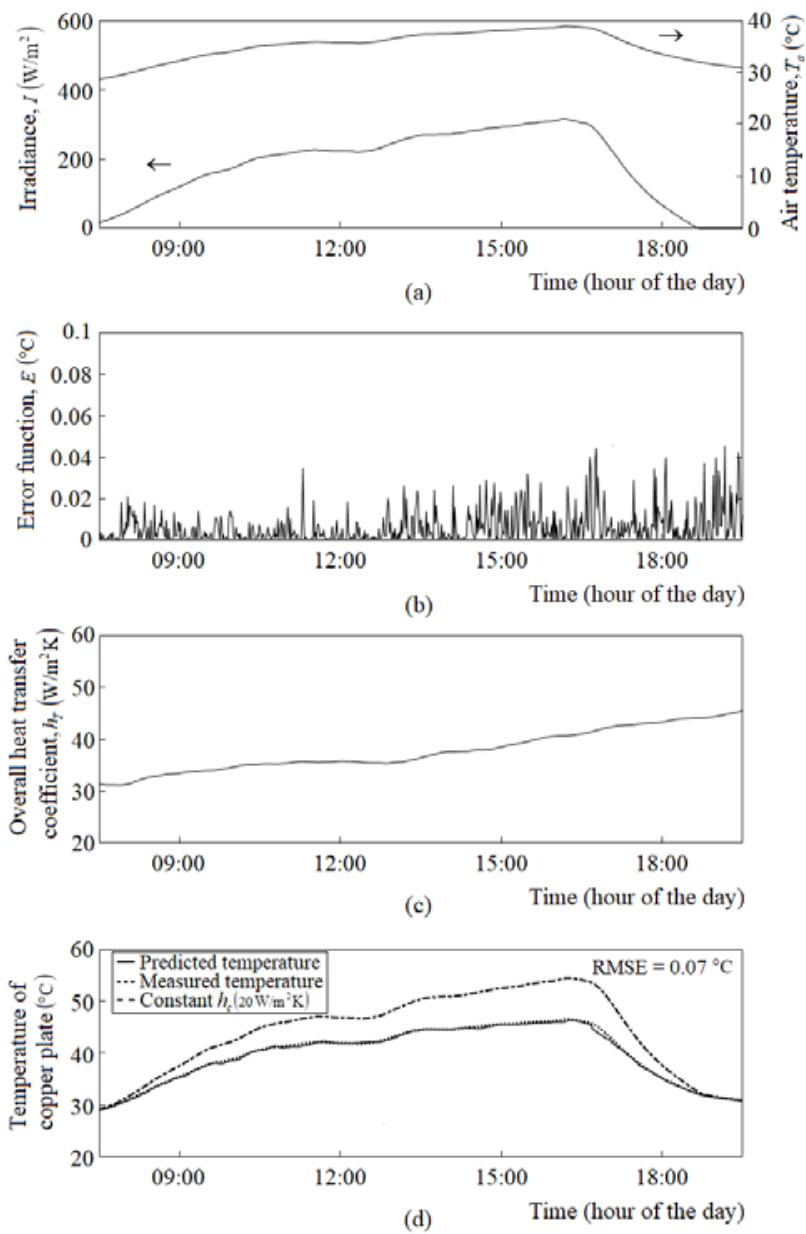

Fig. 4. Experimental results of temperature prediction for the copper plate over time: (a) irradiance and air temperature, (b) error function, (c) calculated overall heat transfer coefficient, (d) predicted and measured temperature of the copper plate. 


\section{Conclusion}

The o verall $\mathrm{h}$ eat $\mathrm{t}$ ransfer co efficient is a cr ucial parameter in determining the heat transferred between a surface and the outdoor air at different temperatures. In this study, $t$ he Adam technique i s i nvestigated $f$ or adaptive learning-rate optimization. This is used for the real-time $\mathrm{d}$ etermination o $\mathrm{f}$ the $\mathrm{o}$ verall heat $\mathrm{t}$ ransfer coefficients via the Seebeck effect in thermoelectric modules. Two thermoelectric modules detect heat transfer as solid surfaces are exposed to the outdoor air. The principle of energy balance and the Seebeck effect are used to determine the overall heat transfer coefficient over time. To demonstrate the viability of the proposed methodology in a real-time i mplementation, the values of the overall heat transfer co efficient of a co pper plate in ambient conditions during the daytime are determined, to $\mathrm{pr}$ edict $\mathrm{t}$ he $\mathrm{c}$ opper plate $\mathrm{t}$ emperatures. $\mathrm{T}$ he temperatures are found to be in good agreement with the measured values, with $\mathrm{RMSE}=0.07{ }^{\circ} \mathrm{C}$. H owever, the predicted t emperatures from the es timated o verall h eat transfer co efficient of $20 \mathrm{~W} / \mathrm{m}^{2} \mathrm{~K}$ do $\mathrm{n}$ ot fit measured temperatures.

\section{References}

1. A. B airi, Q uantification o f t he na tural c onvective heat tr ansfer $\mathrm{f}$ or th e tilt ed a nd $\mathrm{w}$ ire-bonded
QFN32b-PCB el ectronic as sembly, Int. Commun. Heat Mass Transfer, 72, 84-89 (2016)

2. L.E. Mavromatidis, Study of c oupled t ransient radiation-natural co nvention $\mathrm{h}$ eat transfer acr oss rectangular cavities in the vicinity of low emissivity thin $\mathrm{f}$ ilms $\mathrm{f}$ or $\mathrm{i}$ nnovative $\mathrm{b}$ uilding $\mathrm{E}$ nvelope Applications, Energy Build., 120, 114-134 (2016)

3. N. Korprasertsak, and T. Leephakpreeda, Real-time determination of convective heat transfer coefficient via th ermoelectric modules, Journal of Heat Transfer-Transactions of the ASME, 139, 8p (2017)

4. J. Naiborhu, a nd K . S himizu, D irect gr adient descent $\mathrm{c}$ ontrol for $\mathrm{g}$ lobal s tabilization of $\mathrm{g}$ eneral nonlinear c ontrol s ystems, IEICE Transactions on Fundamentals of Electronics Communications and Computer Sciences, 83, 516-523 (2000)

5. D.P. Kingma, a nd J .L. B a, Adam: A method f or stochastic optimization, International Conference on Learning Representations, 1-13 (2015)

6. M. A badi, et al., T ensorFlow: a system for 1 argescale $\mathrm{m}$ achine 1 earning, Proceedings of the 12th USENIX Conference on Operating Systems Design and Implementation (OSDI'16), 265-283 (2016)

7. F.P. Incropera, and D.P. D eWitt, Fundamentals of Heat and Mass Transfer 6th ed. (New Jersey: Wiley, 2007 